\title{
STRATEGIC PIGOUVIAN TAXATION, STOCK EXTERNALITIES AND POLLUTING NON-RENEWABLE RESOURCES*
}

\author{
Santiago J. Rubio and Luisa Escriche**
}

WP-EC 98-23

\author{
Correspondence to S. Rubio: Universitat de València \\ Facultad de Ciencias Económicas y Empresariales \\ Avda de los Naranjos, s/n. Ed. Departamental Oriental. 46022 Valencia \\ E-mail: Santiago.Rubio@uv.es \\ Editor: Instituto Valenciano de Investigaciones Económicas, s.a. \\ First Edition October 1998 \\ ISBN: 84-482-1905-8 \\ Depósito Legal: V-3835-1998
}

IVIE working-papers offer in advance the results of economic research under way in order to encourage a discussion process before sending them to scientific journals for their final publication.

* A $\bar{n}$ early version of this paper was presented at the Workshop on Environment and Natural Resource Economics held at the Institute of Public Economics, University of the Basque Country, Bilbao, January 23-24, 1998. Financial support from the Ministerio de Educación y Cultura (DGES) under Grant PB96-0664-C02-02 is gratefully acknowledged.

** S.J. Rubio y L. Escriche: Universitat de València. 


\title{
STRATEGIC PIGOUVIAN TAXATION, STOCK \\ EXTERNALITIES \\ AND POLLUTING NON-RENEWABLE RESOURCES
}

\author{
Santiago J. Rubio and Luisa Escriche
}

\author{
R E S U M E N
}

Este trabajo propone una extensión del modelo de Wirl y Dockner (1995) diseñado para analizar la interdependencia bilateral a largo plazo entre un cartel exportador de un recurso y una coalición de gobiernos de países importadores. En primer lugar, se incorporan los efectos agotamiento al análisis de las propiedades intertemporales de un impuesto pigouviano. En segundo lugar, se calculan los equilibrios feedback' de Stackelberg. Los resultados muestran que la dinámica del impuesto depende criticamente del nivel del daño medioambiental marginal. Además, también demuestran que el impuesto definido por el equilibrio de Nash perfecto de Markov es un impuesto pigouviano neutral en el sentido que sólo corrige la ineficiencia causada por la externalidad de stock. Sin embargo, para el equilibrio feedback' de Stackelberg el impuesto es ventajoso para los países importadores ya que la imposición pigouviana estratégica reduce el poder de mercado del cartel.

Palabras Clave: Externalidad de stock, imposición pigouviana, impuesto sobre las emisiones de $\mathrm{CO} 2$

Clasificación JEL: D62, F02, H23, Q28, Q48.

\section{A B S T R A C T}

This paper extends Wirl and Dockner's (1995) model designed to analyze the long-term bilateral interdependence between a resource exporting cartel and a coalition of resource importing country governments. Firstly, depletion effects are introduced into the analysis of the intertemporal properties of a pigouvian tax. Secondly, the feedback Stackelberg equilibria are computed. The results show that the dynamics of the tax depends critically on the level of the marginal environmental damage. Moreover, they also show that the tax defined by the Markov- perfect Nash equilibrium is a neutral pigouvian tax in the sense that it only corrects the market inefficiency caused by the stock externality. However, for the feedback Stackelberg equilibrium the tax is advantageous for the importing countries since the strategic pigouvian taxation reduces the market power of the cartel.

Keywords: Stock externality, pigouvian taxation, carbon tax

JEL Classification: D62, F02, H23, Q28, Q48. 


\section{Introduction}

Recently, several papers have been published on the intertemporal properties of a carbon tax. Among them we can quote Hoel (1992, 1993), Sinclair (1992, 1994), Ulph and Ulph (1994), Wirl (1994), Wirl and Dockner (1995), Tahvonen (1995, 1996), Farzin (1996), Farzin and Tahvonen (1996) and Hoel and Kverndokk (1996). These papers can be classified in two groups depending on the approach followed by the authors. A first group formed by Hoel, Sinclair, Ulph and Ulph, Farzin, Farzin and Tahvonen, and Hoel and Kverndokk have focused on the optimal pricing of a non-renewable resource with environmental stock externalities ${ }^{1}$. These papers show that the optimal time path of the carbon tax depends critically on the specification of carbon accumulation process, and in particular on the irreversibility of $\mathrm{CO}_{2}$ emissions. Thus, if the emissions are partially irreversible, as in Farzin and Tahvonen (1996), or if reversibility is costly, as in Farzin (1996), the optimal carbon tax may increase monotonically or have a U-shaped form. However, if reversibility is costless, i.e. if a constant rate of decay of the cumulative emissions is assumed, as Ulph and Ulph (1994) and Hoel and Kverndokk (1996) propose, the dynamics of the optimal tax differs: the tax should initially increase, when the initial stock of cumulative emissions is small, but fall later on when the stock of oil nears exhaustion. This is quite evident when the Farzin and Tahvonen and Hoel and Kverndokk papers are compared, since these two papers only differ essentially in the specification of the cumulative emission dynamics and give different temporal paths for the carbon tax.

The second group of authors follows a somewhat different approach. They have tried to capture the strategic features of the global warming problem, developing a model of long-term bilateral strategic interaction between a resource exporting cartel and a coalition of resource importing governments ${ }^{2}$. In this framework, they have studied the strategic taxation of $\mathrm{CO}_{2}$ emissions by the governments of the importing countries. Their model is a global warming differential game with irreversible emissions where the coalition of

\footnotetext{
${ }^{1}$ Within this group we could differentiate Hoel's approach from the one followed by the rest of the authors. Hoel uses a dynamic pollution game with $N$ countries and defines the optimal carbon tax as the pigouvian tax that reproduces the social optimum. We can also include Forster's (1980) paper in this group, although he does not draw out consequences of his model for the temporal path of a pollution tax.

${ }^{2}$ In fact, their model considers a simple stock externality, of which carbon dioxide is just the most discussed example.
} 
governments choose the carbon tax and the cartel the price ${ }^{3}$. Wirl (1994) and Wirl and Dockner (1995) have shown, for the case of zero extraction cost, that the tax increases monotonically up to the choke price, whereas the price declines monotonically to zero when a Markov-perfect Nash equilibrium in linear strategies is computed. In Tahvonen $(1995,1996)$ the monopolistic extraction is computed as a feedback Stackelberg equilibrium assuming that extraction costs are independent of the resource level. When his results are compared with those of Wirl (1994) and Wirl and Dockner (1995), it turns out that the intertemporal properties of the carbon tax and price are the same irrespective of whether we have a Nash or Stackelberg equilibrium.

In this paper we propose an extension of this approach in two directions. First, we introduce depletion effects into the analysis. We assume that the extraction costs depend positively on the extraction rate and cumulative extractions. Second, we compute not only the Markov-perfect Nash equilibrium with depletion effects but also the two possible feedback Stackelberg equilibria of the game. These two equilibria appear when one of the players enjoys a strategic advantage that in the model means that he moves first. In this way, we extend and complete the analysis of the strategic taxation of $\mathrm{CO}_{2}$ emissions.

Our results show how the depletion effects affect the temporal path of the carbon tax and what the distributive effects of strategic taxation are, making more precise the results obtained by the previous authors. We find that the tax can be decreasing and the price increasing if the environmental damage is not very high, or that the tax and producer price can both be increasing. With depletion effects the dynamics of the tax depends critically on the effect a variation in cumulative extractions has on marginal environmental damage. Nevertheless, if the marginal damage is high enough, the producer price should be decreasing, whereas the tax should be increasing. Furthermore, we find that the tax defined by the Nash equilibrium is a neutral pigouvian tax in the sense that the tax only corrects the market inefficiency caused by the stock externality, and not the inefficiency associated with the market power of the resource cartel. However, if the importing country governments have a strategic advantage, we find that the tax is advantageous for the consumers, since the strategic pigouvian taxation allows importing countries to capture a part of the cartel's profits; although if we look at the aggregate welfare we obtain that there exists a deadweight welfare loss in terms of the present value of the Marshallian aggregate surplus. This transfer is the result of an

\footnotetext{
${ }^{3}$ In Section 4 of Tahvonen's (1996) paper, the case of reversible pollution with depletion effects is studied. But the difficulty of deriving an analytical solution leads the author to compute numerical examples.
} 
initially higher tax and a lower producer price in comparison with the values corresponding to the Nash equilibrium. We also clarify the result obtained by Tahvonen showing that when the resource cartel acts as the leader of the game, the feedback Stackelberg equilibrium is identical to the Markov-perfect Nash equilibrium. This property is explained because the optimal tax for the governments is independent of the producer price.

Finally, we want to point out that the subject of this study is closely related to the literature that analyzes import tariffs as an instrument for gaining from monopsonistic demand or a dominant importer position, and for capturing parts of the resource rent for the importing country. This issue was opened by Bergstrom (1982) and continued, among others, by Brander and Djajic (1983), Karp (1984), Maskin and Newbery (1990) and Karp and Newbery $(1991,1992)$. Among these papers we want to emphasize Karp's (1984) contribution, where this issue is studied using a differential game between the buyers and the sellers of a non-renewable resource. The buyers control the tariff and the sellers the rate of extraction. In this framework the monopsonistic equilibrium has been computed as a Stackelberg equilibrium. This paper is a clear antecedent of Tahvonen's $(1995,1996)$ papers and of our paper. Nevertheless, our contribution differs not only in the subject, where environmental damage is introduced, but also in the nature of the game, since it is assumed that the buyers are price-taker, and the interaction in the market occurs between a resource exporting cartel and a coalition of resource importing country governments. In fact, our model is closer to Lewis, Lindsey and Ware's (1986) approach than to Karp's approach. In Lewis, Lindsey and Ware's (1986) paper the interaction between a resource monopolist and a coalition of consumers in a simple multiperiod model is analyzed. The supplier chooses extraction whereas price-taker consumers act collectively and use the rate of adoption of a substitute to affect strategically the extraction behavior of the supplier and the price of the resource. They compute the Markov-perfect Nash equilibrium and the two open-loop Stackelberg equilibria of the game, and show the effects of commitment on the rate of extraction and the rate of adoption of the substitute.

Our paper is organized as follows: we present the global warming differential game with depletion effects in Section 2; in Section 3 we compute the Markov-perfect Nash equilibrium, and in Section 4 the feedback Stackelberg equilibrium when the governments of the importing countries act as the leader of the game. In Section 5 we develop a comparative analysis of the two equilibria computed in the previous sections. Section 6 summarizes the conclusions and suggests directions for additional research. 


\section{The model}

In this paper we extend Wirl and Dockner's (1995) model ${ }^{4}$. We begin by describing the demand side of the market, assuming that the consumers of the importing countries act as price-taker agents. Under this assumption, we can write the discounted present value of the consumers' net welfare as: $\int_{0}^{\infty} e^{-\delta t}\left\{a q(t)-(1 / 2) q(t)^{2}-[p(t)+\psi(t)] q(t)+R(t)-d z(t)^{2}\right\} d t$, where $a q(t)-(1 / 2) q(t)^{2}$ is the consumers' gross surplus, $q(t)$ is the amount of the resource bought by the importing countries, $p(t)$ is the producer price, $\psi(t)$ is the tax fixed by the importing country governments, $R(t)$ is an income transfer that the consumers receive from the government, and $d z(t)^{2}$ is the environmental or pollution damage function where $z(t)$ is the cumulative emissions and $d$ is a positive parameter. If we consider that global warming is a clear example of a stock externality we have to establish that consumers take as given not only the price of the resource but also the evolution of the accumulated emissions and, moreover, the income transfer, since this is controlled by the governments; so that, finally, the resource demand only depends on consumer price: $q(t)=a-p(t)-\psi(t)$. On the other hand, as $\psi(t)$ represents the tax fixed by the importing country governments, we are implicitly assuming that there exists a coalition or some kind of cooperation among the importing country governments which allows us to represent the resource market as a model of long-term bilateral strategic interaction between a resource exporting cartel (OPEC) and a coalition of resource importing country governments (the West).

The governments are supposed to tax emissions in order to maximize the discounted present value of the net consumers' surplus. We also assume that tax receipts, $\psi(t) q(t)$, are completely refunded to the consumers through the transfer $R(t)$. As a result the optimal time path for the tax is given by the solution of the following problem ${ }^{5}$ :

$$
\begin{gathered}
\max _{\{\psi(t)\}} \int_{0}^{\infty} e^{-\delta t}\left\{a(a-p(t)-\psi(t))-\frac{1}{2}(a-p(t)-\psi(t))^{2}\right. \\
\left.-p(t)(a-p(t)-\psi(t))-d z(t)^{2}\right\} d t
\end{gathered}
$$

where $\delta$ is the discount factor.

\footnotetext{
${ }^{4}$ See that paper for more details. Our version of the game is also closely related to the one developed in section 3 of Tahvonen's (1996) paper. The novelty of our approach in the specification of the model, with respect to these two papers, is that we suppose that average extraction costs depend on cumulative extractions.

${ }^{5}$ In Wirl and Dockner (1995) a study is made of how the Leviathan motive of the governments modifies the temporal path of the tax in a global warming differential game without extraction costs.
} 
The dynamics of cumulative resource consumption determines simultaneously the dynamics of the $\mathrm{CO}_{2}$ concentration in the atmosphere:

$$
\dot{z}(t)=a-p(t)-\psi(t), \quad z(0)=z_{0} \geq 0 .
$$

Following Wirl, Dockner and Tahvonen's approach we suppose that the identity between resource consumption and $\mathrm{CO}_{2}$ emissions is not crucial as long as we can measure oil in terms of that unit that releases one ton of carbon to the atmosphere. This simplified version of the cumulative emission dynamics has also been used by Hoel $(1992,1993)^{6}$.

Let us turn to the other side of the market. We assume that extraction costs depend linearly on the rate of extraction and on the cumulative extractions, $C(q(t), z(t))=[c z(t)] q(t)$, and that the objective of cartelized producers is to define a price strategy that maximizes the discounted present value of profits ${ }^{7}$ :

$$
\max _{\{p(t)\}} \int_{0}^{\infty} e^{-\delta t}\{(p(t)-c z(t))(a-p(t)-\psi(t))\} d t .
$$

Although we incorporate depletion effects into the analysis, we consider that the stock externality is largely irrelevant to the welfare of exporting countries, and that the cumulative extractions are not constrained by the resource in the ground but by its negative impact on extraction costs and climate. Moreover, following Karp (1984), we assume that the producers get no utility from consuming the resource. This assumption is not too great a departure from reality since most major resource exporters consume a negligible portion of their production. Thus, we represent the strategic interactions in the resource market as a differential game between a coalition of importing country governments and cartelized exporters of oil, where the coalition of governments choose the tax and the cartel the price.

\section{A neutral pigouvian tax}

In this section we obtain the solution to the game through the computation of a Markov-perfect Nash equilibrium. We use Markov strategies because these kinds of strategies capture essential strategic interactions, are analytically

\footnotetext{
${ }^{6}$ Given this linear relationship between resource consumption and emissions, $\psi$ could be interpreted as well as a resource import tariff, and the paper as a study on import tariffs and non-renewable resources with stock externalities.

${ }^{7}$ As in our model there is no uncertainty, we can establish that in the equilibrium market resource consumption is equal to extraction rate and, consequently, cumulative emissions equal to cumulative extractions.
} 
tractable and provide a subgame perfect equilibrium which is dynamically consistent.

Markov strategies have to satisfy the following system of Bellman equations ${ }^{8}$ :

$$
\begin{aligned}
\delta W_{1}= & \max _{\{\psi\}}\left\{a(a-p-\psi)-\frac{1}{2}(a-p-\psi)^{2}\right. \\
& \left.-p(a-p-\psi)-d z^{2}+W_{1}^{\prime}(a-p-\psi)\right\}, \\
\delta W_{2}= & \max _{\{p\}}\left\{(p-c z)(a-p-\psi)+W_{2}^{\prime}(a-p-\psi)\right\} .
\end{aligned}
$$

From the first order conditions for the maximization of the r.h.s. of the Bellman equations we get the reaction functions of the governments and producers:

$$
\begin{aligned}
\psi^{N} & =-W_{1}^{\prime}, \\
p^{N} & =\frac{1}{2}\left(a+c z-W_{2}^{\prime}-\psi^{N}\right) .
\end{aligned}
$$

These results establish that the optimal tax is independent of the price fixed by the producers, and that the price and tax are strategic substitutes for the producers ${ }^{9}$. Thus, for the governments of the importing countries the optimal policy consists, as we show below, of defining a neutral pigouvian tax equal to the user cost or shadow price of cumulative emissions. This means that when there is no strategic advantage, i.e. when the two players move simultaneously, the importing countries cannot use the tax for reducing the market power of the cartel, since the optimal tax only corrects the market inefficiency caused by the stock externality. For this reason we define this tax as a neutral pigouvian tax that does not correct the inefficiency associated with the market structure. Notice also that the tax is positive. This differs from the well known proposition, see Buchanan (1969), that establishes that the pigouvian instrument under a monopoly should be a subsidy. The explanation of this divergence is, as Wirl and Dockner (1995) have already pointed out, that the resource market is divided into exporting and importing countries, and the latter do not take into account the producers' surplus in their objective function.

Applying standard techniques of optimal control we get: ${ }^{10}$

$$
\left|W_{1}^{\prime}\right|=\int_{t}^{\infty} e^{-\delta(\tau-t)} 2 d z d \tau-\int_{t}^{\infty} e^{-\delta(\tau-t)} p \frac{\partial p}{\partial z} d \tau
$$

\footnotetext{
${ }^{8}$ Time arguments will be eliminated when no confusion arises.

${ }^{9}$ Superscript $N$ stands for the Markov-perfect Nash equilibrium.

${ }^{10}$ See Kamien and Schwartz (1991, Section 23).
} 
This expression allows us to present an economic interpretation of the user cost or shadow price for the importing countries of an increment in one unit of the cumulative emissions at any time $t$. The first component appears in different papers on the optimal pricing of a non-renewable resource with environmental stock externalities; see, for instance, Farzin (1996) and Farzin and Tahvonen (1996); and it is equal to the discounted present value of the increment in future and present environmental damage caused by an increment at time $t$ of the cumulative emissions. However, the second component only appears when the interdependence between the exporting and importing countries is taken into account; see in this case Tahvonen (1996); and it is equal to the discounted present value of the effect on future and present consumers' welfare caused by the reaction of the exporting countries to a variation of cumulative emissions at time $t$. Notice that the sign of this effect can be positive or negative, depending on the optimal policy or strategy adopted by the cartel.

By substitution of (6) in (7) we get the solution of the price as a function of the first derivatives of the value functions: $p^{N}=\frac{1}{2}\left(a+c z+W_{1}^{\prime}-W_{2}^{\prime}\right)$. Next, incorporating the optimal strategies into the Bellman equations (4) and (5) we eliminate the maximization and obtain, after some calculations, a pair of nonlinear differential equations:

$$
\begin{aligned}
\delta W_{1} & =\frac{1}{8}\left(a-c z+W_{1}^{\prime}+W_{2}^{\prime}\right)^{2}-d z^{2} \\
\delta W_{2} & =\frac{1}{4}\left(a-c z+W_{1}^{\prime}+W_{2}^{\prime}\right)^{2} .
\end{aligned}
$$

Notice, that both value functions depend on $W_{1}^{\prime}+W_{2}^{\prime}$, and so does the consumer price, $\pi=p+\psi$, and the rate of extraction:

$$
\begin{aligned}
\pi^{N} & =\frac{1}{2}\left[a+c z-\left(W_{1}^{\prime}+W_{2}^{\prime}\right)\right] \\
q^{N} & =\frac{1}{2}\left(a-c z+W_{1}^{\prime}+W_{2}^{\prime}\right) .
\end{aligned}
$$

This regular occurrence of the term $W_{1}^{\prime}+W_{2}^{\prime}$ simplifies the solution of the differential equation system (8) and (9) and allows, as happens in Wirl and Dockner's model, a complete analysis of the asymmetric game defined in section 2 .

Before presenting the Markov-perfect Nash equilibrium we want to establish and demonstrate the result we have mentioned above:

Proposition 1 The Markov-perfect Nash equilibrium of the game defines a neutral pigouvian tax. 
Proof. This proof is quite obvious if one realizes, firstly, that in the market there exist two kinds of inefficiencies, one caused by the stock externality and the other by the market power of the producers, and, secondly, that the optimal tax is equal to the user cost of the cumulative emissions. The strategy of the proof is simple: we compute the monopolistic equilibrium without intervention of importing countries' governments, assuming that consumers take into account the damage caused by the cumulative $\mathrm{CO}_{2}$ emissions, and then we check that this equilibrium is identical to the Nash equilibrium. The monopolistic equilibrium is calculated in two stages. In the first stage, price-taker consumers determine the demand function, and, in the second, the cartel decides the price. Then the extraction rate is determined by the demand function.

The Bellman equation for the consumers, if they internalize external costs is:

$$
\delta W_{1}=\max _{\{q\}}\left\{a q-\frac{1}{2} q^{2}-p q-d z^{2}+W_{1}^{\prime} q\right\} .
$$

The maximization of the right-hand side gives us the resource demand function, $q=a-p-W_{1}^{\prime}$, and substitution in the producers' profit function yields:

$$
\delta W_{2}=\max _{\{p\}}\left\{(p-c z)\left(a-p-W_{1}^{\prime}\right)+W_{2}^{\prime}\left(a-p-W_{1}^{\prime}\right)\right\} .
$$

From the maximization of the right-hand side we obtain the same optimal strategy as in the Nash equilibrium, $p^{M}=p^{N}=\frac{1}{2}\left(a+c z+W_{1}^{\prime}-W_{2}^{\prime}\right)$, where the superscript $M$ stands for the monopolistic equilibrium without the inefficiency caused by the stock externality. Then by substitution of the control variables into the Bellman equations, we get the same system of differential equations (8) and (9) and, consequently, the same solution. Therefore, the monopolistic equilibrium, without stock externality, is identical to the Nash equilibrium and we can conclude that the optimal tax defined by the Nash equilibrium is a neutral pigouvian tax in the sense that it only corrects the inefficiency caused by the stock externality and leaves the cartel with its monopolistic profits.

Another possible solution for the game, that we will develop extensively in the next section, can be calculated applying the feedback Stackelberg equilibrium concept. This kind of equilibrium is computed substituting the reaction function of the follower into the Bellman equation of the leader, and then maximizing the right-hand side of the Bellman equation to obtain the optimal strategy. If we now assume that the resource cartel acts as the leader of the game, it is easy to derive the following result: 
Proposition 2 The feedback Stackelberg equilibrium, when the resource cartel acts as leader, is identical to the Markov-perfect Nash equilibrium.

Proof. The proof is quite immediate. By substitution of the reaction function of the governments into the Bellman equation of the cartel we get (13) and then by maximization $p^{S}=p^{N}=\frac{1}{2}\left(a+c z+W_{1}^{\prime}-W_{2}^{\prime}\right)$, where the superscript $\mathrm{S}$ stands for the feedback Stackelberg equilibrium, so that by substitution of control variables into the Bellman equations we have the same system of differential equations (8) and (9) and, consequently, the same solution as for the Markov-perfect Nash equilibrium. $\square$

The reason explaining this result is pretty obvious. As the reaction function of the governments is independent of the producer price, the cartel cannot achieve any profit from its strategic advantage. This also explains why the feedback Stackelberg equilibrium computed by Tahvonen in his 1996 paper presents the same kind of properties as the Markov-perfect Nash equilibrium solved by Wirl and Dockner (1995), and shares some of the results we find in this section ${ }^{11}$.

The solution to the differential equation system (8) and (9) allows us to calculate the linear Markov-perfect Nash equilibrium strategies:

Proposition 3 Let

$$
q^{N}(z)=\left\{\begin{array}{cc}
0, & z_{\infty}^{N} \leq z \\
\frac{1}{2}\left[a+y^{N}-\left(c-x^{N}\right) z\right], & z \leq z_{\infty}^{N}
\end{array}\right.
$$

where

$$
\begin{aligned}
& x^{N}=\frac{1}{2}\left\{2 c+\frac{4}{3} \delta-\left[\frac{16}{3}\left(c \delta+\frac{\delta^{2}}{3}+2 d\right)\right]^{1 / 2}\right\} \\
& y^{N}=-\frac{3 a\left(c-x^{N}\right)}{4 \delta+3\left(c-x^{N}\right)}<0, a+y^{N}>0 \text { and } c-x^{N}>0 .
\end{aligned}
$$

and

$$
z^{N}=\left(z_{0}-z_{\infty}^{N}\right) \exp \left\{-1 / 2\left(c-x^{N}\right) t\right\}+z_{\infty}^{N}
$$

where

$$
z_{\infty}^{N}=\frac{a \delta}{c \delta+2 d}
$$

\footnotetext{
${ }^{11}$ See Tahvonen $(1996$, p.7) and page 16 of this paper for a comparison between our findings and the ones derived by Wirl and Dockner (1995) and Tahvonen (1996).
} 
Then $q^{N}(z)$ constitutes a global asymptotically stable Markov-perfect Nash equilibrium (MPNE) for the infinite horizon differential game under consideration, where $z_{\infty}^{N}$ is the cumulative emission long-run equilibrium and $z(t)$ is the optimal dynamics of the state variable.

Proof. See Appendix A.

As we have just seen in Appendix A, Prop. 3 permits us to calculate the optimal dynamics of the rate of extraction, the producer price, the tax and the consumer price and the discounted present value of welfare for the two players, providing a complete analytical characterization of the solution of the game. The long-run equilibrium value for cumulative emissions has been computed as a particular solution of the differential equation that defines the dynamic restriction of the problem. However, this value can be derived directly using more straightforward economic arguments. The producers exploit the resource until the value function is zero. This implies from (5) that $p-c z=-W_{2}^{\prime}$. On the other hand, the first order condition which gives the reaction function of the producers can also be written as $p-c z-(a-p-\psi)=-W_{2}^{\prime}$, so it follows immediately that $a-p-\psi=q_{\infty}=0$ and $a-p=-W_{1}^{\prime}$, using the reaction function of the governments. With $q_{\infty}=0$ the consumers' value function is $\delta W_{1}=-d z_{\infty}^{2}$ and $-W_{1}^{\prime}=2 d z_{\infty} / \delta$ and by equalization we get $p=a-\left(2 d z_{\infty} / \delta\right)$. Finally, if we assume that extraction of the resource continues until the marginal profit is zero we get $p=c z$, and then we obtain $z_{\infty}=a \delta /(c \delta+2 d)$. This means that the exploitation of the resource must end for a zero marginal profit and value function.

The solution includes the pay-offs of the players, which are given by the value function for the initial value of the state variable, $z_{0}$. For the consumers, we have

$$
W_{1}^{N}\left(z_{0}\right)=\frac{1}{2} \alpha_{1}^{N} z_{0}^{2}+\beta_{1}^{N} z_{0}+\mu_{1}^{N}
$$

where

$$
\begin{aligned}
\alpha_{1}^{N} & =\frac{1}{\delta}\left[\frac{1}{4}\left(c-x^{N}\right)^{2}-2 d\right] \\
\beta_{1}^{N} & =-\frac{a\left(c-x^{N}\right)}{4 \delta+3\left(c-x^{N}\right)} \\
\mu_{1}^{N} & =\frac{1}{8 \delta}\left(a+y^{N}\right)^{2} .
\end{aligned}
$$

For the producers, we have:

$$
W_{2}^{N}\left(z_{0}\right)=\frac{1}{2} \alpha_{2}^{N} z_{0}^{2}+\beta_{2}^{N} z_{0}+\mu_{2}^{N}
$$


where

$$
\begin{aligned}
\alpha_{2}^{N} & =\frac{1}{2 \delta}\left(c-x^{N}\right)^{2} \\
\beta_{2}^{N} & =-\frac{2 a\left(c-x^{N}\right)}{4 \delta+3\left(c-x^{N}\right)} \\
\mu_{2}^{N} & =\frac{1}{4 \delta}\left(a+y^{N}\right)^{2} .
\end{aligned}
$$

From these expressions it is evident that:

Corollary 1 If the initial cumulative emissions are zero, the discounted present values of the net consumers' welfare and profits are positive and equal to (22) and (26).

Proof. Straight from (19) and (23). If we make $z_{0}=0$ in the value functions we have $W_{1}(0)=\frac{1}{8 \delta}\left(a+y^{N}\right)^{2}$ and $W_{2}=\frac{1}{4 \delta}\left(a+y^{N}\right)^{2}$.

However, we cannot extrapolate this result for $z_{0}$ in the interval $\left(0, z_{\infty}^{N}\right)$ because, as we have shown above, the value function for the consumers is strictly negative for $z_{\infty}^{N}$. This means that the extraction of the resource will be profitable only if the initial value for the cumulative extractions is not very high. In particular, the exploitation of the resource will take place if the initial value is in the interval $[0, \bar{z}]$, where $\bar{z}$ is defined by the positive root of the equation $W_{1}(z)=0$. For the producers, the extraction gives a positive pay-off provided that the initial value of the state variable is in the interval $\left[0, z_{\infty}^{N}\right)$. However, as long as the consumers only demand a positive quantity of the resource when the cumulative emissions are below the upper bound, $\bar{z}$, the exploitation of the resource will occur only when the initial value of cumulative emissions is below this critical value. From now on, we will assume that $z_{0}=0$. This simplifies the analysis enormously and helps us to reduce the length of the paper. Nevertheless, we want to point out that the results obtained in the rest of the paper can be generalized for $z_{0}$ in the interval $(0, \bar{z}) \cdot{ }^{12}$

Finally, we compute the dynamics of the rate of extraction, the producer price, the emission tax and the consumer price. To get the temporal paths of these variables we substitute $W_{1}^{\prime}$ and $W_{2}^{\prime}$ in the linear strategies for $q$, $p, \psi$ and $\pi$ by the coefficients of the value functions we have calculated in Appendix A, and then we rearrange the terms and eliminate $z$, using (62):

$$
q^{N}=1 / 2\left(a+y^{N}\right) \exp \left\{-1 / 2\left(c-x^{N}\right) t\right\}
$$

\footnotetext{
${ }^{12}$ The generalization of the results for $z_{0} \in(0, \bar{z})$ is available from the authors.
} 


$$
\begin{aligned}
p^{N} & =\frac{a c \delta}{c \delta+2 d}-\frac{1}{2}\left(c+\alpha_{1}^{N}-\alpha_{2}^{N}\right) z_{\infty}^{N} \exp \left\{-1 / 2\left(c-x^{N}\right) t\right\} \\
\psi^{N} & =\frac{2 a d}{c \delta+2 d}+\alpha_{1}^{N} z_{\infty}^{N} \exp \left\{-1 / 2\left(c-x^{N}\right) t\right\}, \\
\pi^{N} & =a-1 / 2\left(a+y^{N}\right) \exp \left\{-1 / 2\left(c-x^{N}\right) t\right\} .
\end{aligned}
$$

We can now summarize the dynamics of the variables and the long-run equilibrium of the game as follows:

Proposition 4 Along the equilibrium path the rate of extraction decreases while the consumer price increases. The producer price is increasing (decreasing) if $c+\alpha_{1}^{N}-\alpha_{2}^{N}$ is positive (negative) and the emission tax is increasing (decreasing) if $\alpha_{1}^{N}$ is negative (positive). Moreover, the market equilibrium approaches a long-run equilibrium characterized by: $q_{\infty}=0, \pi_{\infty}=a$, $p_{\infty}=\frac{a c \delta}{c \delta+2 d}$ and $\psi_{\infty}=\frac{2 a d}{c \delta+2 d}$.

If we focus on the tax dynamics, we have just seen that this depends on the sign of coefficient $\alpha_{1}^{N}$, which is given by (20). This expression allows us to study the relationship between this coefficient and the damage parameter, $d$, and hence the relationship between the pollution damage and the optimal temporal path of the tax. We know that $\alpha_{1}^{N}$ is positive when $d=0$, see (20). Now, using (15) it is easy to establish that $\alpha_{1}^{N}$ is decreasing with respect to $d$ and that there exists a positive value, that we name as $\underline{d}_{\psi}^{N}$, for which the coefficient of the value function $W_{1}$ is zero. Thus, we get that when $d$ is lower than $\underline{d}_{\psi}^{N}$ the emission tax is decreasing, and when $d$ is higher than $\underline{d}_{\psi}^{N}$ it is increasing. Or, in other words, if the pollution damage is high with respect to extraction costs the optimal tax would have to be increasing.

The interpretation of this result is quite intuitive if one realizes that the differential game under consideration integrates characteristics of two models with different properties. Making $c=0$ we have Wirl and Dockner's (1995) model, and for $d=0$ we have a version of Karp's (1984) model where $\psi$ must be interpreted as an import tariff and the issue addressed is whether it is advantageous for the importing countries to fix a tariff on the resource. In the first case, we can check that $x^{N}$ and $\alpha_{1}^{N}$ are negative for any positive value of parameter $d$ and that the tax is always increasing ${ }^{13}$. For $c=0,(29)$ is written as $\psi^{N}=a+\alpha_{1}^{N} z_{\infty}^{N} \exp \left\{x^{N} t / 2\right\}$ and then $d \psi^{N} / d t>0$. This means that if there are no depletion effects, the optimal tax for the importing countries must rise. In the second case, it is evident that $\alpha_{1}^{N}$ is positive and the tax is decreasing. For $d=0,(29)$ is written as $\psi^{N}=\alpha_{1}^{N} z_{\infty}^{N} \exp \left\{-1 / 2\left(c-x^{N}\right) t\right\}$

\footnotetext{
${ }^{13}$ In fact, the tax is also increasing when the extraction costs are quadratic but independent of the cumulative extractions, as has been shown by Tahvonen (1996).
} 
and then $d \psi^{N} / d t<0$, since the sign of $c-x^{N}$ does not change ${ }^{14}$. We obtain, in this case, that, when the environmental damage is zero and the depletion effects are positive, the optimal policy for the importing countries is a decreasing import tariff. Thus, we have two trends of opposite sign acting in our game, and we find that when the pollution damage is high with respect to extraction costs, the increasing trend dominates, and the tax is increasing. However, if on the contrary the pollution damage is low, the decreasing trend dominates and the tax is decreasing.

If we focus now on the temporal path of the producer price we get the same kind of results. The dynamics of the variable depends on the sign of the following expression:

$$
c+\alpha_{1}^{N}-\alpha_{2}^{N}=c-\frac{1}{4 \delta}\left(c-x^{N}\right)^{2}-\frac{2 d}{\delta} .
$$

It is easy to show that for $d$ equal to zero this expression is positive. As $c+\alpha_{1}^{N}-\alpha_{2}^{N}$ can be written as $c-x^{N}+2 \alpha_{1}^{N}$, we can use this last expression for determining the sign of the former. For $d=0$ we have found that $\alpha_{1}^{N}$ is positive; then $c+\alpha_{1}^{N}-\alpha_{2}^{N}$ is positive if $c-x^{N}$ is positive for $d=0$. To calculate $c-x^{N}$ we use (15), yielding:

$$
c-x^{N}=\frac{1}{2}\left\{-\frac{4}{3} \delta+\left[\frac{16}{3}\left(c \delta+\frac{\delta^{2}}{3}\right)\right]^{1 / 2}\right\} .
$$

If we suppose that $c-x^{N}$ is negative or zero, the following must be satisfied:

$$
\left[\frac{16}{3}\left(c \delta+\frac{\delta^{2}}{3}\right)\right]^{1 / 2} \leq \frac{4}{3} \delta .
$$

Taking the square of this inequality we get $16 / 3(c \delta) \leq 0$, which is a contradiction. As a result we have to accept that $c-x^{N}$ is positive and conclude that $c+\alpha_{1}^{N}-\alpha_{2}^{N}$ is positive as well. Now, applying calculus to (31) and using (15) we can establish that $c+\alpha_{1}^{N}-\alpha_{2}^{N}$ is decreasing with respect to $d$ and that there exists a positive value, that we represent by $\underline{d}_{p}^{N}$, for which the producer price is constant. Thus, we get that when $d$ is lower that $\underline{d}_{p}^{N}$ the price is increasing, whereas it is decreasing if $d$ is higher than $\underline{d}_{p}^{N}$. Or, in other words, if the pollution damage is high with respect to extraction costs the optimal producer price must be decreasing. This result is also justified by the two opposite trends we have found in our model. For $c=0$ we know that the producer price is decreasing, but for $d=0$ it is increasing. Consequently, when these two parameters are positive we can obtain both types

\footnotetext{
${ }^{14}$ This is shown in the next paragraph.
} 
of dynamics depending on the values of the parameters. On the other hand, the compatibility between a decreasing quantity and price can be explained by resorting to the reaction function (7). According to this function the producer price and the tax are strategic substitutes since the tax reduces the marginal revenue of the cartel. Moreover, the reaction function establishes that the price increases, coteris paribus, with the complete marginal cost of the resource, defined by the marginal extraction cost plus the user cost, $c z-W_{2}^{\prime}$. Then as the tax increases and the complete marginal cost decreases along the equilibrium path, when the pollution damage is high enough, we find that the dynamics of the producer price have to be decreasing. Obviously, as the extraction rate is decreasing, the negative effect of an increase of the tax on the quantity must be higher than the positive effect of a reduction of the complete marginal cost on the extraction rate.

Finally, we can describe the different temporal paths that the tax and producer price can follow, depending on the environmental damage. First, we define the existing relationship between $\underline{d}_{\psi}^{N}$ and $\underline{d}_{p}^{N}$. As $c+\alpha_{1}^{N}-\alpha_{2}^{N}$ is equal to $c-x^{N}+2 \alpha_{1}^{N}$, we get that when $d=\underline{d}_{\psi}^{N}, c+\alpha_{1}^{N}-\alpha_{2}^{N}=c-x^{N}$, which is positive for any positive value of $d$, as is established in (16). Thus, $c+\alpha_{1}^{N}-\alpha_{2}^{N}$ is zero for a higher value than $\underline{d}_{\psi}^{N}$, and then we can conclude that $\underline{d}_{\psi}^{N}$ is lower than $\underline{d}_{p}^{N}$. Now, we are able to present the different temporal trajectories depending on the value of parameter $d$. Given $c$ and $\delta$, if $d$ is lower than $\underline{d}_{\psi}^{N}$ the price is increasing and the tax is decreasing; if $d$ is in the interval $\left(\underline{d}_{w}^{N}, \underline{d}_{p}^{N}\right)$ the price and tax are increasing; and, finally, if $d$ is higher than $\underline{d}_{p}^{N}$ the price is decreasing but the tax is increasing. This last relationship can also be presented as follows:

Corollary 2 If an increase in cumulative emissions has an effect on marginal damage higher than $2 \underline{d}_{p}^{N}$, the optimal producer price is decreasing whereas the optimal tax is increasing.

Notice that the effect of an increase in cumulative emissions on marginal damage is given by $\partial^{2} D / \partial z^{2}$ which is equal to $2 d$, so that it is sufficient with $\partial^{2} D / \partial z^{2}$ higher than $2 \underline{d}_{p}^{N}$ to have an increasing tax with a decreasing price.

This result already appears in Wirl and Dockner (1995) and Tahvonen's (1996) papers, but as long as they do not take into account the depletion effects on the extraction of the resource, the pollution tax is increasing and the producer price is decreasing for all $d$. In this paper we complete their analysis showing that the tax can be decreasing and the price increasing if the pollution damage is not very high, or that the tax and producer price can both be increasing. 


\section{A feedback Stackelberg equilibrium}

In this section we turn to considering the resource market as a Stackelberg game where the governments of the importing countries act as the leader of the game. In this way, we make a second extension of the differential game designed by Wirl and Dockner (1995) to analyze the long-term bilateral interdependence between a resource exporting cartel and a coalition of resource importing country governments. We are now interested in studying how the solution of the game changes when the coalition of importing countries has a strategic advantage.

To study this case we assume that we have a repeated two stage game where the leader moves first. To find the leader's optimal policy we proceed by backward induction substituting the reaction function of the follower in the Bellman equation of the leader, and computing the optimal strategy by maximization of the right-hand side of this equation. This procedure selects only the time-consistent strategies. The resulting outcome is a feedback Stackelberg solution which is a Markov-perfect equilibrium.

The substitution of the reaction function (7) in Bellman equation (4) yields:

$$
\begin{aligned}
\delta W_{1}= & \max _{\{\psi\}}\left\{\frac{1}{4}\left(a+\psi-c z+W_{2}^{\prime}\right)\left(a-\psi-c z+W_{2}^{\prime}\right)\right. \\
& +\frac{1}{2}\left(a-\psi-c z+W_{2}^{\prime}\right) W_{1}^{\prime} \\
& \left.-\frac{1}{8}\left(a-\psi-c z+W_{2}^{\prime}\right)^{2}-d z^{2}\right\} .
\end{aligned}
$$

Maximizing the r.h.s. we obtain the optimal policy or strategy for the tax, and using again the reaction function of the resource cartel the optimal policy for the producer price:

$$
\begin{aligned}
\psi^{S} & =\frac{1}{3}\left(a-c z-2 W_{1}^{\prime}+W_{2}^{\prime}\right) \\
p^{S} & =\frac{1}{3}\left(a+2 c z+W_{1}^{\prime}-2 W_{2}^{\prime}\right) .
\end{aligned}
$$

By substitution of the optimal tax into the Bellman equation of the importing country governments (32) and of the tax and producer price into the Bellman equation of the resource cartel (5) we eliminate the maximization and obtain, after some manipulations, the following pair of nonlinear differential equations:

$$
\delta W_{1}=\frac{1}{6}\left(a-c z+W_{1}^{\prime}+W_{2}^{\prime}\right)^{2}-d z^{2},
$$




$$
\delta W_{2}=\frac{1}{9}\left(a-c z+W_{1}^{\prime}+W_{2}^{\prime}\right)^{2}
$$

Notice, that again both value functions depend on $W_{1}^{\prime}+W_{2}^{\prime}$ and so do the consumer price and the rate of extraction:

$$
\begin{aligned}
\pi^{S} & =\frac{1}{3}\left[2 a+c z-\left(W_{1}^{\prime}+W_{2}^{\prime}\right)\right] \\
q^{S} & =\frac{1}{3}\left(a-c z+W_{1}^{\prime}+W_{2}^{\prime}\right) .
\end{aligned}
$$

The solution to the differential equation system we have just defined allows us to obtain the linear feedback Stackelberg equilibrium strategies:

Proposition 5 Let

$$
q^{S}(z)=\left\{\begin{array}{cc}
0, & z_{\infty}^{S} \leq z \\
\frac{1}{3}\left[a+y^{S}-\left(c-x^{S}\right) z\right], & z \leq z_{\infty}^{S}
\end{array}\right.
$$

where

$$
\begin{gathered}
x^{S}=\frac{1}{2}\left\{2 c+\frac{9}{5} \delta-\left[\frac{9}{5}\left(4 c \delta+\frac{9}{5} \delta^{2}+8 d\right)\right]^{1 / 2}\right\}, \\
y^{S}=-\frac{5 a\left(c-x^{S}\right)}{9 \delta+5\left(c-x^{S}\right)}, a+y^{S}>0 \text { and } c-x^{S}>0,
\end{gathered}
$$

and

$$
z^{S}=\left(z_{0}-z_{\infty}^{S}\right) \exp \left\{-1 / 3\left(c-x^{S}\right) t\right\}+z_{\infty}^{S}
$$

where

$$
z_{\infty}^{S}=\frac{a \delta}{c \delta+2 d}
$$

Then $q^{S}(z)$ constitutes a global asymptotically stable feedback Stackelberg equilibrium (FSE) for the infinite differential game under consideration, where $z_{\infty}^{S}$ is the cumulative emissions long-run equilibrium.

Proof. The proof follows step by step the one of Prop. 3. For this reason we omit it.

This proposition establishes that the long-run equilibrium for the cumulative emissions is the same as in the MPNE of the game. In fact, it is easy to check that the long-run equilibrium values are the same for all the variables. The explanation of this result is pretty obvious, if one remembers how the 
cumulative emission long-run equilibrium value has been derived in Section 3 from the Bellman equations and the first order conditions associated with these equations. The point is that the way of solving the game does not change the conditions that define the long-run equilibrium of the game. To obtain $z_{\infty}$ in Section 3 we have used the Bellman equation and the reaction function of the producers and the Bellman equation of the governments. Now, as we use the same reaction function of the producers to solve the feedback Stackelberg equilibrium, we derive the long-run equilibrium resorting to the same equations and the same conditions: the producers exploit the resource until the value function and the marginal profit are zero, and, consequently, we get the same value and the same long-run equilibrium. This does not mean that the game has an identical solution in both cases, since the way of solving the game affects the approach paths to the long-run equilibrium.

The solution includes, as for the MPNE, the pay-offs for the players, which are given for the value function for the initial value of the state variable, $z_{0}=0$,

$$
\begin{aligned}
& W_{1}^{S}(0)=\mu_{1}^{S}=\frac{1}{6 \delta}\left(a+y^{S}\right)^{2}, \\
& W_{2}^{S}(0)=\mu_{2}^{S}=\frac{1}{9 \delta}\left(a+y^{S}\right)^{2} .
\end{aligned}
$$

We find again that if the initial cumulative emissions are zero, the discounted present values of the net consumers' welfare and profits are positive.

Following the same procedure than we used to compute the MPNE, we can derive the dynamics of the rate of extraction, the producer price, the emission tax and the consumer price.

$$
\begin{aligned}
q^{S} & =1 / 3\left(a+y^{S}\right) \exp \left\{-1 / 3\left(c-x^{S}\right) t\right\}, \\
p^{S} & =\frac{a c \delta}{c \delta+2 d}-\frac{1}{3}\left(2\left(c-\alpha_{2}^{S}\right)+\alpha_{1}^{S}\right) z_{\infty} \exp \left\{-1 / 3\left(c-x^{S}\right) t\right\}, \\
\psi^{S} & =\frac{2 a d}{c \delta+2 d}+\frac{1}{3}\left(c+2 \alpha_{1}^{S}-\alpha_{2}^{S}\right) z_{\infty} \exp \left\{-1 / 3\left(c-x^{S}\right) t\right\}, \\
\pi^{S} & =a-1 / 3\left(a+y^{S}\right) \exp \left\{-1 / 3\left(c-x^{S}\right) t\right\} .
\end{aligned}
$$

We can now summarize the dynamics of the variables and the long-run equilibrium of the game as follows:

Proposition 6 Along the equilibrium path the rate of extraction decreases while the consumer price increases. The producer price is increasing (decreasing) if $2\left(c-\alpha_{2}^{S}\right)+\alpha_{1}^{S}$ is positive (negative), and the emission tax is increasing (decreasing) if $c+2 \alpha_{1}^{S}-\alpha_{2}^{S}$ is negative (positive). Moreover, the market equilibrium approaches a long-run equilibrium characterized by: $q_{\infty}=0, \pi_{\infty}=a$, $p_{\infty}=\frac{a c \delta}{c \delta+2 d}$ and $\psi_{\infty}=\frac{2 a d}{c \delta+2 d}$. 
By comparison of the two solutions we can check that the determinants of the tax and producer price dynamics and the justification of the results obtained are the same as in the MPNE. For the FSE, there are only changes in the critical value of the parameter $d$, which determines whether the tax and producer price are increasing or decreasing.

In order to not be repetitive we only present here the expressions which explain the dynamics of the tax and producer price:

$$
\begin{aligned}
c+2 \alpha_{1}^{S}-\alpha_{2}^{S} & =c+\frac{4}{9 \delta}\left(c-x^{S}\right)^{2}-\frac{4 d}{\delta}, \\
2\left(c-\alpha_{2}^{S}\right)+\alpha_{1}^{S} & =2 c-\frac{1}{9 \delta}\left(c-x^{S}\right)^{2}-\frac{2 d}{\delta} .
\end{aligned}
$$

From these expressions, using (40), we obtain the critical values $\underline{d}_{\psi}^{S}$ and $\underline{d}_{p}^{S}$, defined as the values for which the tax and the producer price are constant, i.e. the values for which $c+2 \alpha_{1}^{S}-\alpha_{2}^{S}$ and $2\left(c-\alpha_{2}^{S}\right)+\alpha_{1}^{S}$ are zero.

Finally, we can describe the different temporal paths that the tax and producer price can follow, depending on the pollution damage. First, we obtain the relationship existing between $\underline{d}_{\psi}^{S}$ and $\underline{d}_{p}^{S}$. As $c+2 \alpha_{1}^{S}-\alpha_{2}^{S}$ is equal to $c-x^{S}+3 \alpha_{1}^{S}$, and $2\left(c-\alpha_{2}^{S}\right)+\alpha_{1}^{S}$ is equal to $2\left(c-x^{S}\right)+3 \alpha_{1}^{S}$, we know that when $d=\underline{d}_{\psi}^{S}, c-x^{S}+3 \alpha_{1}^{S}=0$ and, consequently, $2\left(c-x^{S}\right)+3 \alpha_{1}^{S}$ is positive, so that this last expression is zero for a value higher than $\underline{d}_{\psi}^{S}$, and we can conclude that $\underline{d}_{\psi}^{S}$ is lower than $\underline{d}_{p}^{S}$. Established the comparison between $\underline{d}_{\psi}^{S}$ and $\underline{d}_{\psi}^{S}$; we can characterize the temporal trajectories of the tax and producer price, depending on the value of parameter $d$. Given $c$ and $\delta$, if $d$ is lower than $\underline{d}_{w}^{S}$ the price is increasing and the tax is decreasing, if $d$ is in the interval $\left(\underline{d}_{\psi}^{S}, \underline{d}_{p}^{S}\right)$ the price and tax are increasing and, finally, if $d$ is higher than $\underline{d}_{p}^{S}$ the price is decreasing and the tax is increasing. This last relationship can also be presented as follows:

Corollary 3 If an increase in cumulative emissions has an effect on marginal damage higher than $2 \underline{d}_{p}^{S}$, the optimal producer price is decreasing whereas the optimal tax is increasing.

Remember that the effect of an increase in cumulative emissions on marginal damage is given by $\partial^{2} D / \partial z^{2}$ which is equal to $2 d$, and therefore it is a sufficient condition that $\partial^{2} D / \partial z^{2}$ to be higher than $2 \underline{d}_{p}^{S}$ to have an increasing tax with a decreasing price.

\section{$5 \quad$ An advantageous pigouvian tax}

In this section we develop the comparison between the two equilibria computed in the previous sections. First, we focus on the players' pay-offs. From 
this comparison we obtain that when the governments can fix the tax before the producers fix the price, the tax allows them to increase the welfare of the consumers. In this sense, we say that the tax is advantageous for the consumers of resource importing countries, since the strategic pigouvian taxation of $\mathrm{CO}_{2}$ emissions supposes a transfer from the cartel to the consumers. However, if we look at the aggregate welfare, we find that there is a deadweight welfare loss in terms of discounted present value of Marshallian aggregate surplus. Hence, although the tax is advantageous for the importing countries when the governments move first, the efficiency of the market decreases. The following proposition summarizes these results:

Proposition 7 When the importing country governments have a strategic advantage the consumers' welfare increases, and the producers' profits and aggregate welfare decrease with respect to Markov-perfect Nash equilibrium.

Proof. See Appendix B.

In this framework, the resource cartel could be interested in negotiating with the coalition of importing country governments a collateral payment in order to reduce the negative effect of the governments' strategic advantage on its profits. As long as the aggregate pay-offs are higher for the MPNE, the resource cartel could transfer to the importing countries a part of its profits in exchange for a Nash taxing strategy. Even in such a situation the cartel could still get a pay-off higher than in the FSE. This opens up the analysis of the strategic interaction between a resource cartel and a coalition of resource importing country governments to the application of cooperative game theory.

In the second place, we compare the optimal strategies and the initial values of the tax and producer price. We can summarize the findings as follows:

Proposition 8 The FSE is more conservative than the MPNE, i.e., given any resource stock level, the Nash extraction rate exceeds the Stackelberg extraction rate. Moreover, the initial value for the tax in the MPNE is lower than in the FSE, whereas this relationship reverses for the producer price.

Proof. See Appendix C.

Notice that these results are independent of the parameter values. The strategic advantage of the importing country governments translates into a higher initial value for the emission tax and a lower value for the producer price, thus causing a transfer of rents from producers to consumers. In this 
framework, the application of a tax in the importing countries is advantageous for the consumers, who pay a lower producer price. Observe that for the consumers' welfare this is the relevant variable, as can be seen in expression (1), since we have assumed that the government completely reimburses through an income transfer the tax collected from the consumers ${ }^{15}$.

It can be also established that if the environmental damage is low enough, the MPNE tax is always lower than the FSE tax. However, if the contrary occurs, i.e., if the environmental damage is not low enough, the emission tax for the MPNE is first below but later above the emission tax for the FSE. Something similar happens to the producer price. If the environmental damage is low enough, the MPNE producer price is always higher than the FSE producer price. If this is not the case the temporal paths intersect once. Nevertheless, even in this case, the net effect on consumers' welfare is positive, as we have already shown in Prop. 7. This is better understood if it is remembered that the discount effect gives greater weight to the pay-offs closer to the present. And to conclude, we compare the approach paths in more detail:

Proposition 9 The cumulative extractions for the MPNE are higher than for the FSE for all $t \in(0, \infty)$. However, this variable converges asymptotically to the same value in both cases. The rate of extraction for the MPNE is first above but later below the FSE rate of extraction. This relationship reverses for the consumer price. Moreover, if the environmental damage is high enough, the emission tax for the MPNE is first below but later above the FSE emission tax. This relationship reverses for the producer price.

Proof. See Appendix D.

\section{Conclusions}

We have examined the strategic pigouvian taxation of $\mathrm{CO}_{2}$ emissions in the framework of a global warming differential game with depletion effects between a resource exporting cartel and a coalition of resource importing country governments. We have determined the intertemporal properties of the carbon tax showing that these depend on the importance of environmental damage in comparison with depletion effects. Nevertheless, we have found that if environmental damage is high enough the tax should be increasing

\footnotetext{
${ }^{15}$ See Wirl and Dockner (1995) for a study of how the Leviathan motive of the governments affects the MPNE of a global warming differential game without extraction costs.
} 
and the producer price decreasing. Besides, we have shown that if the governments do not have any strategic advantage, the pigouvian tax only corrects the market inefficiency caused by the stock externality and that, in that case, the strategic taxation of emissions does not affect the monopolistic power of the cartel. If the governments act as the leader of the game, the consumers get a higher welfare, but, the market efficiency decreases with respect to the Markov-perfect Nash equilibrium. In this case the tax is advantageous for the importing countries but it causes a welfare loss in terms of the Marshallian aggregate surplus present value in comparison with the Markov-perfect Nash equilibrium. Moreover, although the FSE strategy is more conservationist, its effect is only transient because the long-run equilibrium is the same, since the market approaches the same stock of cumulative emissions in both cases. The result is that neither from an environmental point of view nor from an economic perspective is it advantageous that a country or region moves first. However, if this does occur, we have shown that the resource importing country can use an emission tax to increase the welfare that consumers obtain from consumption of the resource.

The scope of our results is limited by the specification of the game and the irreversibility assumption for the emissions. However, this approach seems to us, for the moment, inevitable to make the analysis tractable ${ }^{16}$. Obviously, these limitations point out directions for additional research, although in the framework of the model developed in this paper some additional extensions could be considered. We have supposed that the stock externality is largely irrelevant to the welfare of exporting countries. However, this reduces the global character of the greenhouse effect. For this reason it would be interesting to introduce into the analysis environmental damage along with domestic energy consumption in the exporting countries, and to study the issue of the unilateral taxation of $\mathrm{CO}_{2}$ emissions. Another extension could be to increase the number of the importing countries to analyze the issue of cooperation among the importing countries to control the global warming problem. Finally, cooperative game theory could be applied when the importing country governments have some strategic advantage, since in this case cooperation could increase the pay-offs of the two players.

\footnotetext{
${ }^{16}$ Notice that the irreversibility of emissions allows us to work with a unique state variable. See Tahvonen (1996), Section 4 to get an idea of the difficulties that appear when two state variables are considered.
} 


\section{A Derivation of linear Markov-perfect Nash equilibrium strategies}

The linear strategies can be determined by proposing quadratic solutions for the value functions:

$$
\begin{aligned}
& W_{1}(z)=\frac{1}{2} \alpha_{1}^{N} z^{2}+\beta_{1}^{N} z+\mu_{1}^{N} \\
& W_{2}(z)=\frac{1}{2} \alpha_{2}^{N} z^{2}+\beta_{2}^{N} z+\mu_{2}^{N} .
\end{aligned}
$$

Substituting the value functions and their first derivatives into the Bellman equations and equating coefficients yields the following system of equations ${ }^{17}$

$$
\begin{aligned}
\frac{\delta}{2} \alpha_{1} & =\frac{1}{8}\left(c-\alpha_{1}-\alpha_{2}\right)^{2}-d, \\
\delta \beta_{1} & =-\frac{1}{4}\left(a+\beta_{1}+\beta_{2}\right)\left(c-\alpha_{1}-\alpha_{2}\right), \\
\delta \mu_{1} & =\frac{1}{8}\left(a+\beta_{1}+\beta_{2}\right)^{2}, \\
\frac{\delta}{2} \alpha_{2} & =\frac{1}{4}\left(c-\alpha_{1}-\alpha_{2}\right)^{2} \\
\delta \beta_{2} & =-\frac{1}{2}\left(a+\beta_{1}+\beta_{2}\right)\left(c-\alpha_{1}-\alpha_{2}\right), \\
\delta \mu_{2} & =\frac{1}{4}\left(a+\beta_{1}+\beta_{2}\right)^{2} .
\end{aligned}
$$

Even though this system of equations presents a recursive structure its solution is quite long and complex. However, a simple transformation enormously simplifies its solution. We define $x=\alpha_{1}+\alpha_{2}$ and $y=\beta_{1}+\beta_{2}$ and add equations (52) and (55) and equations (53) and (56), obtaining a simplified system of equations in the new variables:

$$
\begin{aligned}
\delta x & =\frac{3}{4}(c-x)^{2}-2 d, \\
\delta y & =-\frac{3}{4}(a+y)(c-x) .
\end{aligned}
$$

In the light of these two equations and the differential equations (8) and (9), it appears that the solution corresponds to an aggregate value function $V=W_{1}+W_{2}=\frac{1}{2} x z^{2}+y z+w$ whose coefficients must satisfy equation: $\delta V=3 / 8\left(a-c z+V^{\prime}\right)^{2}-d z^{2}$. Equation (58) has two real roots. We choose

\footnotetext{
${ }^{17}$ The superscript $\mathrm{N}$ will be omitted when no confusion arises.
} 
the one which satisfies the stability condition: $d \dot{z} / d z<0$. To apply this condition, we write the rate of extraction (11) in terms of coefficients $x$ and $y$, resulting in $q=1 / 2[a+y-(c-x) z]$, and then as $\dot{z}=q$ we have that $d \dot{z} / d z=-1 / 2(c-x)<0$, which requires that $c-x>0$. Expression (15) is the root that satisfies this condition. Given the value of $x,(59)$ yields the value of the coefficient $y$; see (16). Knowledge of these two coefficients is sufficient for the computation of the rate of extraction, as can be seen above, and the consumer price $\pi$. To obtain the producer price and the tax strategies, we need to solve (52), (53), (55) and (56), using (58) and (59), to obtain $\alpha_{1}, \beta_{1}, \alpha_{2}$ and $\beta_{2}$.

Finally, we solve the first order differential equation $\dot{z}=1 / 2[a+y-(c-$ $x) z]$ to obtain the long-run cumulative extraction equilibrium. The solution to this equation is:

$$
z=C \exp \{-1 / 2(c-x) t\}+\frac{a+y}{c-x}
$$

where $(a+y) /(c-x)$ is the particular solution $\dot{z}=0$ and $C$ is an integration constant. Then, as $c-x$ is positive, the long-run equilibrium is the particular solution. If we substitute $a+y$ in the long-run equilibrium value we get:

$$
z_{\infty}=\frac{4 a \delta}{4 c \delta-4 \delta x+3(c-x)^{2}},
$$

which can be rewritten as:

$$
z_{\infty}=\frac{4 a \delta}{4 c \delta+8 d}=\frac{a \delta}{c \delta+2 d}
$$

taking into account that $-4 \delta x+3(c-x)^{2}=8 d$, according to (58). Then using the initial condition, $z_{0}$, to eliminate the integration constant we get the optimal dynamics of the state variable of the game:

$$
z=\left(z_{0}-z_{\infty}\right) \exp \{-1 / 2(c-x) t\}+z_{\infty},
$$

and by substitution in the linear strategies the dynamics of the rest of the variables of the model, achieving a complete analytical characterization of the Markov-perfect Nash equilibrium.

\section{B Proof of Proposition 7}

First, we compare the players' pay-offs. For the consumers the effect of the importing country governments' strategic advantage on the discounted 
present value they get from consumption of the resource, is given by the difference between $W_{1}^{N}(0)$ and $W_{1}^{S}(0)$. If we look at these two expressions, it is easy to check that the relationship existing between the pay-offs depends on the relationship between $y^{N}$ and $y^{S}$. To establish the sign of this relationship, let's suppose that $y^{S} \leq y^{N}$. This implies that:

$$
-\frac{5 a\left(c-x^{S}\right)}{9 \delta+5\left(c-x^{S}\right)} \leq-\frac{3 a\left(c-x^{N}\right)}{4 \delta+3\left(c-x^{N}\right)} .
$$

Multiplying the numerators by the denominators and the resulting expression by -1 , we obtain:

$$
27\left(c-x^{N}\right) \leq 20\left(c-x^{S}\right)
$$

where

$$
\begin{aligned}
& c-x^{N}=\frac{1}{2}\left\{-\frac{4}{3} \delta+\left[\frac{16}{3}\left(c \delta+\frac{\delta^{2}}{3}+2 d\right)\right]^{1 / 2}\right\}, \\
& c-x^{S}=\frac{1}{2}\left\{-\frac{9}{5} \delta+\left[\frac{9}{5}\left(4 c \delta+\frac{9 \delta^{2}}{5}+8 d\right)\right]^{1 / 2}\right\} .
\end{aligned}
$$

Substituting these two expressions in (63) we get:

$$
27\left[\frac{16}{3}\left(c \delta+\frac{\delta^{2}}{3}+2 d\right)\right]^{1 / 2} \leq 20\left[\frac{9}{5}\left(4 c \delta+\frac{9 \delta^{2}}{5}+8 d\right)\right]^{1 / 2},
$$

and raising to square and simplifying we get a contradiction: $1008 c \delta+$ $2016 d \leq 0$, and we must admit that $y^{N}<y^{S}$, and hence that $W_{1}^{N}(0)<$ $W_{2}^{S}(0)$. As one would expect, the strategic advantage of importing country governments has a positive effect on the consumers' welfare.

For the exporting countries the pay-off difference is given by the difference between $W_{2}^{N}(0)$ and $W_{2}^{S}(0)$. We have just obtained that $y^{N}<y^{S}$, but as $1 / 9 \delta<1 / 4 \delta$ we cannot directly establish the comparison. Let's suppose that $W_{2}^{N}(0) \leq W_{2}^{S}(0)$. This inequality implies that:

$$
3\left(a+y^{N}\right) \leq 2\left(a+y^{S}\right),
$$

where

$$
\begin{aligned}
a+y^{N} & =\frac{4 a \delta}{4 \delta+3\left(c-x^{N}\right)} \\
a+y^{S} & =\frac{9 a \delta}{9 \delta+5\left(c-x^{S}\right)} .
\end{aligned}
$$


Multiplying the numerators by the denominators and rearranging terms we obtain:

$$
6 \delta+10\left(c-x^{S}\right) \leq 9\left(c-x^{N}\right)
$$

and substituting (64) and (65) yields:

$$
\begin{aligned}
& 6 \delta+10\left[\frac{9}{5}\left(4 c \delta+\frac{9 \delta^{2}}{5}+8 d\right)\right]^{1 / 2} \\
\leq & 9\left[\frac{16}{3}\left(c \delta+\frac{\delta^{2}}{3}+2 d\right)\right]^{1 / 2} .
\end{aligned}
$$

Finally, raising to square we get:

$$
216 \delta^{2}+288 c \delta+576 d+120 \delta\left[\frac{9}{5}\left(4 c \delta+\frac{9 \delta^{2}}{5}+8 d\right)\right]^{1 / 2} \leq 0
$$

which is a contradiction, and we conclude that the producers obtain a lower pay-off when the importing country governments move first.

To complete the analysis we compute the variation in the aggregate payoffs, which is given by the difference between:

$$
V^{N}(0)=W_{1}^{N}(0)+W_{2}^{N}(0)=\frac{3}{8 \delta}\left(a+y^{N}\right)^{2},
$$

and

$$
V^{S}(0)=W_{1}^{S}(0)+W_{2}^{S}(0)=\frac{5}{18 \delta}\left(a+y^{S}\right)^{2} .
$$

Let's suppose that $V^{N}(0) \leq V^{S}(0)$; then

$$
27\left(a+y^{N}\right)^{2} \leq 20\left(a+y^{S}\right)^{2},
$$

substituting (66) and (67) for $a+y^{N}$ and $a+y^{S}$ we obtain:

$$
4\left(9 \delta+5\left(c-x^{S}\right)\right)^{2} \leq 15\left(4 \delta+3\left(c-x^{N}\right)\right)^{2} .
$$

Developing the squares yields:

$$
\begin{aligned}
& 84 \delta^{2}+360 \delta\left(c-x^{S}\right)+100\left(c-x^{S}\right)^{2} \\
\leq & 360 \delta\left(c-x^{N}\right)+135\left(c-x^{N}\right)^{2} .
\end{aligned}
$$


Now substituting (64) and (65) for $c-x^{N}$ and $c-x^{S}$ we get:

$$
\begin{aligned}
& 42 \delta+90\left[\frac{9}{5}\left(4 c \delta+\frac{9 \delta^{2}}{5}+8 d\right)\right]^{1 / 2} \\
\leq & 90\left[\frac{16}{3}\left(c \delta+\frac{\delta^{2}}{3}+2 d\right)\right]^{1 / 2} .
\end{aligned}
$$

Finally, raising to square and simplifying terms, we obtain the following contradiction:

$$
\begin{aligned}
0 \geq & 15120 \delta+13608 \delta^{2}+30240 d \\
& +7560 \delta\left[\frac{9}{5}\left(4 c \delta+\frac{9 \delta^{2}}{5}+8 d\right)\right]^{1 / 2} .
\end{aligned}
$$

The sign of this inequality leads us to conclude that the aggregate pay-offs decrease when the governments enjoy a strategic advantage ${ }^{18}$.

\section{Proof of Proposition 8}

In this proof we compare the optimal linear strategies and the initial values of the tax and the producer price. If we take into account that the strategies are linear and defines the same rate of extraction for the same long-run equilibrium value of the cumulative emissions, it is sufficient to know the relative position of the independent terms to make the comparison. From the comparison between the producer pay-offs, we know that $W_{2}^{S}(0)=1 / 9 \delta(a+$ $\left.y^{S}\right)^{2}<W_{2}^{N}(0)=1 / 4 \delta\left(a+y^{N}\right)^{2}$, which implies that $1 / 3\left(a+y^{S}\right)<1 / 2(a+$ $\left.y^{N}\right)$, and that the independent term for the MPNE strategy is higher than the one for the FSE strategy. Thus, given any resource stock level, the Nash extraction rate exceeds the Stackelberg extraction rate. Furthermore, taking into account the relation between the independent terms, the comparison between the slope of the strategies is immediate. As long as $q_{\infty}^{N}=q_{\infty}^{S}$ and $z_{\infty}^{N}=z_{\infty}^{S}=z_{\infty}$ we have that

$$
\frac{1}{2}\left(a+y^{N}\right)-\frac{1}{2}\left(c-x^{N}\right) z_{\infty}=\frac{1}{3}\left(a+y^{S}\right)-\frac{1}{3}\left(c-x^{S}\right) z_{\infty}
$$

that can be rewritten as

$$
\frac{1}{2}\left(a+y^{N}\right)-\frac{1}{3}\left(a+y^{S}\right)=\left[\frac{1}{2}\left(c-x^{N}\right)-\frac{1}{3}\left(c-x^{S}\right)\right] z_{\infty}
$$

\footnotetext{
${ }^{18}$ These results can also be obtained for $z_{0} \neq 0$, provided the exploitation of the resource is profitable. However, as we indicated in Section 3, we will not develop here the complete analysis of this issue. Details are available from the authors.
} 
Then, as the difference in the l.h.s. is positive, we have that

$$
1 / 3\left(c-x^{S}\right)<1 / 2\left(c-x^{N}\right) .
$$

Now, we focus on the comparison between the initial values of the tax and producer price. For $t=0$, we know from $(29)$ and $(48)$ that $\psi^{N}(0)-\psi^{S}(0)=$ $\left[\alpha_{1}^{N}-1 / 3\left(c+2 \alpha_{1}^{S}-\alpha_{2}^{S}\right)\right] z_{\infty}$, where $\alpha_{1}^{N}-1 / 3\left(c+2 \alpha_{1}^{S}-\alpha_{2}^{S}\right)=\alpha_{1}^{N}-1 / 3(c-$ $\left.\alpha_{1}^{S}-\alpha_{2}^{S}+3 \alpha_{1}^{S}\right)=\alpha_{1}^{N}-\alpha_{1}^{S}-1 / 3\left(c-x^{S}\right)$ and as $c-x^{S}$ is positive, the sign of the difference between the initial values of the tax depends on the sign of the difference between the parameters: $\alpha_{1}^{N}-\alpha_{1}^{S}$, where $\alpha_{1}^{N}$ is given by (20) and $\alpha_{1}^{S}$ is obtained in the same way as $\alpha_{1}^{N}$ and is equal to $1 / \delta\left[1 / 3\left(c-x^{S}\right)^{2}-2 d\right]$. So we can write:

$$
\alpha_{1}^{N}-\alpha_{1}^{S}=\frac{1}{4 \delta}\left(c-x^{N}\right)^{2}-\frac{1}{3 \delta}\left(c-x^{S}\right)^{2}
$$

where we can observe that the sign of this difference depends on the relationship between $x^{N}$ and $x^{S}$. Let's suppose that $x^{N} \leq x^{S}$. Using (15) from Prop. 3 and (40) from Prop. 5 yields:

$$
\left[\frac{9}{5}\left(4 c \delta+\frac{9}{5} \delta^{2}+8 d\right)\right]^{1 / 2} \leq \frac{7}{15}\left[\frac{16}{3}\left(c \delta+\frac{\delta^{2}}{3}+2 d\right)\right]^{1 / 2}
$$

and raising to square, we get:

$$
\frac{4}{3} \delta^{2}+2 c \delta+4 d \leq \delta\left[\frac{16}{3}\left(c \delta+\frac{\delta^{2}}{3}+2 d\right)\right]^{1 / 2}
$$

and raising to square again we have the following contradiction: $(c \delta)^{2}+$ $4 c d \delta+4 d \leq 0$. This contradiction allows us to establish that $x^{S}<x^{N}$ which implies that $c-x^{N}<c-x^{S}$ and that $\alpha_{1}^{N}-\alpha_{1}^{S}<0$, with the final result that $\psi^{N}(0)<\psi^{S}(0)$. For the comparison of the initial producer price we obtain that $p^{N}(0)-p^{S}(0)=\left[1 / 3\left(2\left(c-\alpha_{2}^{S}\right)+\alpha_{1}^{S}\right)-1 / 2\left(c+\alpha_{1}^{N}-\alpha_{2}^{N}\right)\right] z_{\infty}$, using (28) and (47) for $t=0$, where $1 / 3\left(2\left(c-\alpha_{2}^{S}\right)+\alpha_{1}^{S}\right)-1 / 2\left(c+\alpha_{1}^{N}-\alpha_{2}^{N}\right)=$ $\alpha_{1}^{S}-\alpha_{1}^{N}+2 / 3\left(c-x^{S}\right)-1 / 2\left(c-x^{N}\right)$ is positive, since we have just concluded that $c-x^{N}$ is less than $c-x^{S}$ and $\alpha_{1}^{N}$ is less than $\alpha_{1}^{S}$. Thus, we can conclude that $p^{S}(0)<p^{N}(0)$.

\section{Proof of Proposition 9}

We begin comparing the temporal paths of cumulative extractions. For the MPNE the dynamics of this variable is given by (62) that, for $z_{0}=0$, can 
be written as $z^{N}=z_{\infty}\left(1-\exp \left\{-1 / 2\left(c-x^{N}\right) t\right\}\right)$. For the FSE, following the same steps as we have presented in Appendix $A$ for the computation of the MPNE, we get $z^{S}=z_{\infty}\left(1-\exp \left\{-1 / 3\left(c-x^{S}\right) t\right\}\right)$, so that the difference between the temporal paths is:

$$
z^{N}-z^{S}=z_{\infty}\left[\exp \left\{-1 / 3\left(c-x^{S}\right) t\right\}-\exp \left\{-1 / 2\left(c-x^{N}\right) t\right\}\right],
$$

which is positive for all $t \in(0, \infty)$ since $1 / 3\left(c-x^{S}\right)<1 / 2\left(c-x^{N}\right)$, as we have shown in the proof of Prop. 8 . For the comparison of the extraction rate temporal paths we use (27) and (46). In this case the difference between the two temporal paths is given by the following expression:

$$
\begin{aligned}
q^{N}-q^{S}= & 1 / 2\left(a+y^{N}\right) \exp \left\{-1 / 2\left(c-x^{N}\right) t\right\} \\
& -1 / 3\left(a+y^{S}\right) \exp \left\{-1 / 3\left\{c-x^{S}\right) t\right\} .
\end{aligned}
$$

For $t=0$ we know that the difference $q^{N}(0)-q^{S}(0)$ is positive, since $1 / 2(a+$ $\left.y^{N}\right)>1 / 3\left(a+y^{S}\right)$, as we established in the comparison of the linear strategies of the two equilibria; see also previous proof. For $t \neq 0$ we can find the number of intersection points from the equation $q^{S}-q^{N}=0$. This equation can be written as:

$$
\frac{1 / 3\left(a+y^{S}\right)}{1 / 2\left(a+y^{N}\right)}=\exp \left\{1 / 3\left(c-x^{S}\right) t-1 / 2\left(c-x^{N}\right) t\right\}
$$

where the 1.h.s. is a positive constant less than one and the r.h.s. is a decreasing and convex function which takes the value one for $t=0$, and tends to zero when $t$ tends to infinity. This shows us that the temporal paths cut each other once in the interval $[0, \infty)$, and, consequently, we can establish that for $0 \leq t<t^{\prime}$, where $t^{\prime}$ is the solution to equation (71), the MPNE extraction rate is higher than the FSE extraction rate, whereas for $t^{\prime}<t$ the relationship between the two temporal trajectories is the contrary. If we now compare the temporal trajectories for the consumer price defined by (30) and (49), it is evident that the relationship between the prices is the inverse of the one we have just established for the quantities, and that the intersection point is the same for the prices as for the quantities.

The comparison between the emission tax and producer price requires the analysis of the five possible combinations of the different trajectories the variables can take, according to what the values of the parameters are. However, in order to avoid an excessively long comparative analysis, we restrict ourselves in this appendix to the case of an increasing tax and a decreasing price, which corresponds with the case of a damage parameter above the critical values, $\underline{d}_{\psi}^{N}, \underline{d}_{p}^{N}, \underline{d}_{\psi}^{S}$ and $\underline{d}_{p}^{S}$, defined in sections 3 and 4 . Nevertheless, 
we present below, in a summarized form, a complete comparison for these two variables.

We begin with the tax. Using (29) and (48) we obtain the difference between the two equilibria for the temporal path of the tax:

$$
\begin{aligned}
\psi^{N}-\psi^{S}= & z_{\infty}\left[\alpha_{1}^{N} \exp \left\{-1 / 2\left(c-x^{N}\right) t\right\}\right. \\
& \left.-1 / 3\left(c+2 \alpha_{1}^{S}-\alpha_{2}^{S}\right) \exp \left\{-1 / 3\left(c-x^{S}\right) t\right\}\right] .
\end{aligned}
$$

We have already established in Prop. 8 that $\psi^{N}(0)<\psi^{S}(0)$. Now we study if there exists a point of intersection of the trajectories. If this is the case, the equation $\psi^{H}-\psi^{S}=0$ must have a solution given by

$$
\frac{1 / 3\left(c+2 \alpha_{1}^{S}-\alpha_{2}^{S}\right)}{\alpha_{1}^{N}}=\exp \left\{1 / 3\left(c-x^{S}\right) t-1 / 2\left(c-x^{N}\right) t\right\} .
$$

From the proof of Prop. 8 we know that $\alpha_{1}^{N}<1 / 3\left(c+2 \alpha_{1}^{S}-\alpha_{2}^{S}\right)$ and if we assume that the two trajectories are increasing we have moreover that $\alpha_{1}^{N}<1 / 3\left(c+2 \alpha_{1}^{S}-\alpha_{2}^{S}\right)<0$. For this reason the l.h.s of $(72)$ is a positive constant less than unity, whereas the r.h.s is the same expression as appears on the r.h.s of (71), so that equation (72) also has a unique solution and we can conclude that the MPNE tax is first below the FSE tax but that later this relationship reverses and the FSE tax is above the MPNE tax. For the other possible cases, that are defined on the basis of the following inequalities: $\alpha_{1}^{N}<1 / 3\left(c+2 \alpha_{1}^{S}-\alpha_{2}^{S}\right)=0$ ( $\psi^{N}$ increasing and $\psi^{S}$ constant), $\alpha_{1}^{N}<0<1 / 3\left(c+2 \alpha_{1}^{S}-\alpha_{2}^{S}\right)\left(\psi^{N}\right.$ increasing and $\psi^{S}$ decreasing $), \alpha_{1}^{N}=$ $0<1 / 3\left(c+2 \alpha_{1}^{S}-\alpha_{2}^{S}\right)\left(\psi^{N}\right.$ constant and $\psi^{S}$ decreasing $)$, and $0<\alpha_{1}^{N}<$ $1 / 3\left(c+2 \alpha_{1}^{S}-\alpha_{2}^{S}\right)\left(\psi^{N}\right.$ and $\psi^{S}$ decreasing $)$, it is easy to show that the FSE tax is higher than the MPNE tax for all $t \in[0, \infty)$. In all these cases the strategic advantage of the importing country governments implies that the emission tax for the FSE would always be above the tax for the MNPE' ${ }^{19}$.

Finally, we compare the producer price. From (28) and (47) we find that the difference between the producer prices is:

$$
\begin{aligned}
p^{N}-p^{S}= & z_{\infty}\left[-1 / 3\left(2\left(c-2 \alpha_{2}^{S}\right)+\alpha_{1}^{S}\right) \exp \left\{-1 / 3\left(c-x^{S}\right) t\right\}\right. \\
& \left.-1 / 2\left(c+\alpha_{1}^{N}-\alpha_{2}^{N}\right) \exp \left\{-1 / 2\left(c-x^{N}\right) t\right\}\right] .
\end{aligned}
$$

We have already established in Prop. 8 that $p^{S}(0)<p^{N}(0)$. Now we define the equation for $t, p^{N}-p^{S}=0$, and show that this equation has an unique intersection point, defined by the solution to:

$$
\frac{1 / 3\left(2\left(c-\alpha_{2}^{S}\right)+\alpha_{1}^{S}\right)}{1 / 2\left(c+\alpha_{1}^{N}-\alpha_{2}^{N}\right)}=\exp \left\{1 / 3\left(c-x^{S}\right) t-1 / 2\left(c-x^{N}\right) t\right\}
$$

\footnotetext{
${ }^{19}$ Notice also that $\psi^{N}$ cannot be decreasing if $\psi^{S}$ is increasing.
} 
The r.h.s. is the same as in equations (71) and (72) and has, therefore, the same properties. Moreover, we know from the proof of Prop. 8 that $1 / 2\left(c+\alpha_{1}^{N}-\alpha_{2}^{N}\right)<1 / 3\left(2\left(c-2 \alpha_{2}^{S}\right)+\alpha_{1}^{S}\right)$. If we now assume that the two temporal paths are decreasing we also have that $1 / 2\left(c+\alpha_{1}^{N}-\alpha_{2}^{N}\right)<$ $1 / 3\left(2\left(c-\alpha_{2}^{S}\right)+\alpha_{1}^{S}\right)<0$ and, consequently, that the l.h.s is a positive constant lower than unity, resulting in the same kind of equation as we obtained for the rate of extraction and tax, and as in these cases we find a unique solution for the equation. This result allows us to conclude that the FSE producer price is initially lower than the MPNE producer price and that this relationship persists until $t^{\prime}$, defined by equation (73), and from that moment changes such that the FSE producer price is above the MPNE.

For the other possible profiles of the price trajectories, which are determined by the following inequalities: $1 / 2\left(c+\alpha_{1}^{N}-\alpha_{2}^{N}\right)<1 / 3\left(2\left(c-\alpha_{2}^{S}\right)+\alpha_{1}^{S}\right)=$ $0\left(p^{N}\right.$ decreasing and $p^{S}$ constant $), 1 / 2\left(c+\alpha_{1}^{N}-\alpha_{2}^{N}\right)<0<1 / 3\left(2\left(c-\alpha_{2}^{S}\right)+\alpha_{1}^{S}\right)$ $\left(p^{N}\right.$ decreasing and $p^{S}$ increasing $), 1 / 2\left(c+\alpha_{1}^{N}-\alpha_{2}^{N}\right)=0<1 / 3\left(2\left(c-\alpha_{2}^{S}\right)+\alpha_{1}^{S}\right)$ $\left(p^{N}\right.$ constant and $p^{S}$ increasing) and $0<1 / 2\left(c+\alpha_{1}^{N}-\alpha_{2}^{N}\right)<1 / 3(2(c-$ $\left.\alpha_{2}^{S}\right)+\alpha_{1}^{S}$ ) (both prices increasing), the FSE price is found to be less than the MNPE price for all $t \in[0, \infty)^{20}$.

\section{References}

[1] Bergstrom, T.C. (1982), 'On capturing oil rents with a national excise tax', American Economic Review 72:194-201.

[2] Brander, J. and Djajic, S. (1983), 'Rent-extracting tariffs and the management of exhaustible resources', Canadian Journal of Economics 16:288-298.

[3] Buchanan, J.M. (1969), 'External diseconomies and corrective taxes and market structure', American Economic Review 59:174-177.

[4] Farzin, Y.H. (1996), 'Optimal pricing of environmental and natural resource use with stock externalities', Journal of Public Economics 62:3157.

[5] Farzin, Y.H. and Tahvonen, O. (1996), 'Global carbon cycle and the optimal time path of a carbon tax', Oxford Economic Papers 48:515536.

[6] Forster, B.A. (1980), 'Optimal energy use in a polluted environment', Journal of Environmental Economics and Management 7:321-333.

\footnotetext{
${ }^{20}$ Notice also that $p^{N}$ cannot be increasing if $p^{S}$ is decreasing.
} 
[7] Hoel, M. (1992), 'Emission taxes in a dynamic international game of $\mathrm{CO}_{2}$ emissions', in R. Pethig (ed.), Conflicts and cooperation in managing environmental resources, Berlin:Springer-Verlag, Ch. 2.

[8] Hoel, M. (1993), 'Intertemporal properties of an international carbon tax', Resource and Energy Economics 15:51-70.

[9] Hoel, M. and Kverndokk, S. (1996), 'Depletion of fossil fuels and the impacts of global warming,, Resource and Energy Economics 18:115136.

[10] Kamien, M.I. and Schwartz, N. (1991), Dynamic optimization. The calculus of variations and optimal control in economics and management, 2nd ed., Amsterdam:North-Holland.

[11] Karp, L. (1984), 'Optimality and consistency in a differential game with non-renewable resources', Journal of Economic Dynamics and Control 8:73-97.

[12] Karp, L. and Newbery, D.M. (1991), 'Optimal tariffs on exhaustible resources', Journal of International Economics 30:285-299.

[13] Karp, L. and Newbery, D.M. (1992), 'Dynamically consistent oil import tariffs', Canadian Journal of Economics 25:1-21.

[14] Lewis, T., Lindsey, R. and Ware, R. (1986), 'Long-term bilateral monopoly: The case of an exhaustible resource', Rand Journal of Economics 17:89-104.

[15] Maskin, E. and Newbery, D.M. (1990), 'Disadvantageous oil tariffs and dynamic consistency', American Economic Review 80:143-156.

[16] Sinclair, P. (1992), 'High does nothing and rising is worse: Carbon taxes should keep declining to cut harmful emissions', Manchester School 60:41-52.

[17] Sinclair, P. (1994), 'On the trend of fossil fuel taxation', Oxford Economic Papers 46:869-877.

[18] Tahvonen, O. (1995), 'International $\mathrm{CO}_{2}$ taxation and the dynamics of fossil fuel markets', International Tax and Public Finance 2:261-278.

[19] Tahvonen, O. (1996), 'Trade with polluting nonrenewable resources', Journal of Environmental Economics and Management 30:1-17. 
[20] Ulph, A. and Ulph, D. (1994), 'The optimal time path of a carbon tax', Oxford Economic Papers 46:857-868.

[21] Wirl, F. (1994), 'Pigouvian taxation of energy for flow and stock externalities and strategic, noncompetitive energy pricing', Journal of Environmental Economics and Management 26:1-18.

[22] Wirl, F. and Dockner, E. (1995), 'Leviathan governments and carbon taxes: Costs and potential benefits', European Economic Review 39:1215-1236. 